\title{
Epidural Tramadol with low dose local anaesthetics for anaesthesia and postoperative analgesia in NYHA class III orthopaedic patients - A prospective randomized controlled study
}

\author{
Paranjpe JS ${ }^{1}$, Gaikwad SA ${ }^{2}$, Patil MS ${ }^{3}$, Bandgar $\mathrm{SP}^{4}$, Deshpande TS ${ }^{5}$ \\ 1,2,3,4,5 (Department of Anaesthesiology, Bharati Vidyapeeth University Medical College \& Hospital, Sangli, \\ Maharashtra, India)
}

\begin{abstract}
Aims \& Objectives: 1.To assess the effect of epidural Tramadol with low dose local anaesthetics on quality of anaesthesia, postoperative analgesia, haemodynamic stability, and outcome in patients undergoing major orthopaedic surgeries on lower limb.

Patients \& Method: One hundred \& seventy NYHA class III patients (age >60 yr) posted for major orthopaedic surgery on lower limbs during $1^{\text {st }}$ July 2007 to $31^{\text {st }}$ July 2010 were selected for the study. They were randomized into control (group A) \& study group (group B). Group A received sixteen $m l$ of an equal mixture of $1 \%$ Xylocaine and $0.25 \%$ Bupivacaine while Group B received Tramadol $50 \mathrm{mg}$ in addition to the mixture of LAs epidurally. Inadequate level of sensory block necessitated further supplementation with $5 \mathrm{ml}$ of $0.25 \%$ Bupivalocaine. For postoperative analgesia, group A received $5 c c 0.125 \%(10 \mathrm{mg})$ Bupivacaine while group B received $5 c c(50 \mathrm{mg})$ Tramadol.Anaesthetic, haemodynamic effects, pain scores, blood pressure, respiratory rate, side effects, complications and level of satisfaction were monitored for 72 hours. Adequacy of postoperative pain relief was judged by VAS. Statistical analyses were done by mean \pm standard deviation. Correlation was examined with Pearson correlation coefficients (significance assumed with $p<0.05$ ). Results: Pain scores were significantly decreased in group B. Reduction in mean arterial pressure, heart rate and respiratory rate were found in both the groups but were not significantly different between the two groups. The incidence of postoperative complications was more in group A. Level of sedation and satisfaction was better in group $B$.

Conclusion: Use of low dose local anaesthetics with Tramadol was safe, reliable \& effective in producing adequate sensory \& motor blockade. The technique provided better haemodynamic stability \& pain relief with lesser postoperative complications in HRCP (High risk cardiac patients).
\end{abstract}

Abbreviations: LDEA- Low dose epidural anaesthesia, MAP-Mean arterial pressure, LA- Local anaesthetic, VAS- Visual analogue scale

Key words: Cardiac patient, Low dose epidural anaesthesia, Postoperative analgesia, Epidural Tramadol

\section{Introduction}

Due to change in demographic profile and change in attitude towards surgical treatment, the population of surgical patients aged 60 years and older has been steadily increasing. Since degenerative changes of aging reduce reserves, age is an independent mortality \& morbidity risk factor. Impaired autonomic function in cardiac patients causes inability to compensate for adverse drug effects on cardiovascular system. ${ }^{[1]}$

When preservative free narcotics are beyond the reach due to various reasons, Epidural Tramadol may be a suitable alternative in carefully selected high risk cardiac patients when respiratory depression is concerned. Easy availability at cheaper price and safety in institute with limited well trained manpower are motivations for the use of Tramadol.

\section{Study design}

One hundred \& seventy NYHA class III patients (age >60 yr) posted for major orthopaedic surgery on lower limbs during $1^{\text {st }}$ July 2007 to $31^{\text {st }}$ July 2010 were enrolled for the study. They were randomized into control (group A) \& study group (group B). Since all the patients selected were high risk cardiac patients, their medical treatment was optimized \& continued. Bridging strategy was used for anticoagulant therapy.

[Figure 1 - Bridging strategy] ${ }^{[2]}$

All the patients received $0.2 \mathrm{mg}$ Glycopyrrolate intravenously as a premedication. Group A received a total volume $16 \mathrm{cc}$ of $1 \%$ Xylocaine $(80 \mathrm{mg})+0.25 \%$ Bupivacaine $(20 \mathrm{mg})$, while group B received $50 \mathrm{mg}$ Tramadol in addition to LAs (Local Anaesthetics). Incremental doses given were $5 \mathrm{cc}$ of $0.25 \%$ Bupivacaine for both the groups. For postoperative analgesia, group A received 5cc of 0.125\% (10 mg) Bupivacaine while group 
B received $5 \mathrm{cc}$ of $(50 \mathrm{mg}$ ) Tramadol. LDEA (Low dose epidural anaesthesia) was used as a sole technique for anesthesia \& postoperative analgesia.

Motor blockage was assessed by Bromage score while autonomic blockage by heart rate \& MAP (Mean arterial pressure) using noninvasive cardiac monitors. Dermatomal level of sensory anesthesia was judged by Verbal rating scale (VRS) and Postoperative analgesia by Visual analogue scale (VAS).All the patients were monitored for 72 hours from the time of epidural injection.

Total five patients were excluded from the study due to inadvertent dural puncture during catheter insertion (2), postoperative catheter migration (1), inability to follow the protocol since patient had postoperative angina (1) \& due to technical error (1).

[Figure 2 - Disease wise distribution of the patients]

Change in parameters compared to baseline values were considered significant for fall in heart rate $>10 \%$, fall in MAP $>20 \%$, fall in $\mathrm{SpO} 2>5 \%$. While respiratory rate $<12$ breaths / min was considered as respiratory depression.

All the patients were monitored for early signs of neurologic dysfunction and for presenting symptoms of spinal epidural hematoma like new back pain, radicular pain, and progressive lower extremity weakness for 3 postoperative days.

\section{Observations and results}

1. The time to reach the level of sensory blockade up to T10 (onset) was $23+/-7 \mathrm{~min}$ in both the groups.

2. The duration of anaesthesia was significantly prolonged in group B.

3. Failure of technique (patchy anaesthesia) was evident in one case. The patient was supplemented with intravenous administration of Midazolam, Fentanyl and Propofol in a drip form.

4. Level of motor blockade was found to be low (Bromage score 2) in 2/165 patients.

5. Reduction in respiratory rate was more evident in group B but it was never less than $17 / \mathrm{min}$ and was not associated with fall in $\mathrm{SpO}$. [Figure 3]

6. Levels of sedation and satisfaction judged by a simple four point scale were found significantly better in group B. $(\mathrm{p}<0.05)$

7. Intra operative decrease in MAP of more than $20 \%$ was noted in $(2 / 165)$ patients, which occurred 10 minutes after first LA administration.

8. Cardiostability was achieved after 48 hours postoperatively in both the groups which was better in group B but with no statistical significance. $(\mathrm{p}<0.07)$ [Figure 4,5]

9. The duration and quality of postoperative analgesia was significantly better in group B which resulted in reduced frequency of doses. $(\mathrm{p}<0.01)$ [Figure 6]

10. Though incidence of post operative complications was low, it was more with group A (8 Vs 2). [Figure 7]

11. The signs of neurologic dysfunction or symptoms of spinal epidural hematoma were not observed.

12. Group B patients had lesser hospital stay by 1-2 days and showed better outcome.

\section{Discussion}

Risk of severe and prolonged hypotension is associated with spinal anaesthesia. This is due to the rapid extension of the sympathetic block, hindering cardiovascular adaptation and causing significant morbidity and mortality. ${ }^{[3]}$

Elderly cardiac patients have impaired autonomic function, reduced compliance of arteries, loss of functional reserves hence are unable to withstand cardiac decompensation. ${ }^{[1]}$ Essential requirements of anaesthesia for such patients are avoiding tachycardia and extremes of blood pressure, both of which adversely affect the balance between oxygen supply and demand. ${ }^{[4]}$ In elderly patients free lignocaine concentration is found to be higher than that in younger age group, necessitating use of lower doses. ${ }^{[5]}$

It is documented in the literature that the patients undergoing major surgery with epidural anaesthesia and analgesia have stable cardiovascular parameters, minimal neuroendocrine response, lesser respiratory complications including SIRS and sepsis, lower incidence of thromboembolic events, less blood loss, reduced hospital stay and better pain control. ${ }^{[6,7,8]}$ Epidural techniques are particularly effective at providing dynamic analgesia (pain on movement), allowing the patient to mobilize and resume normal activities unlimited by pain. Parenteral opioids, even with patient-controlled delivery systems, cannot predictably provide the same quality of analgesia. ${ }^{[9]}$ Opioids acting on spinal cord receptors provide distinct advantage over its systemic administration for better quality of analgesia, lower sedation scores, preservation of physiological function and improved outcome. ${ }^{[10,11]}$

Some controversy exists with regards to reduced coagulation and neuraxial anaesthesia. The estimated incidence of epidural hematoma with concurrent administration of antithrombotic drugs (Low molecular weight heparins) is 1: $\square 3,100$ for continuous epidural anaesthesia. ${ }^{[12]}$ According to the recommendation of the 
American Society of Regional Anesthesia and Pain Medicine (ASRA), warfarin therapy must be stopped ideally

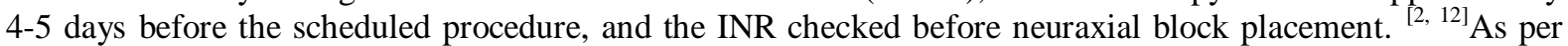
ASRA guidelines, patients on low molecular weight heparin (LMWH) anticoagulation have not been found to be at an increased risk of bleeding in high-risk groups. Administration of LMWH the night before surgery does not interfere with epidural block placement on the day of surgery. Patients receiving postoperative LMWH thromboprophylaxis may safely be administered for both single-dose and continuous catheter techniques. ${ }^{[2,12]}$

The potential of low dose epidural anaesthesia (LDEA) to decrease postoperative morbidity and mortality has been demonstrated by numerous studies. ${ }^{[6,7,8,12]}$ A combination of local anaesthetics and opioid lowers the dose requirements for each drug, as well as lowers the frequency of side effects. ${ }^{[12]}$

A synthetic opioid Tramadol acts through multiple mechanisms and has a low risk of post operative respiratory depression and negligible haemodynamic effects. ${ }^{[13,14]}$ Its analgesic activity is mediated through an agonist action at all types of opioid receptors with some $\mu$ receptor selectivity. In addition it inhibits noradrenaline uptake and stimulates serotonin release. Increased concentrations of these neurotransmitters in the descending pathways enhance the analgesic response. Up to $60 \%$ of the analgesic activity of Tramadol is thought to be mediated through its nonopioid actions. ${ }^{[13]}$

Hypotension and bradycardia, when occur, are attributed to the reduction of sympathetic outflow via opioid receptors in the sympathetic ganglia. ${ }^{[12]}$ There is evidence that regional anaesthesia, particularly epidural blockade, attenuates surgical stress by blocking afferent neural stimuli from reaching the central nervous system, as well as by blocking the efferent activation of the sympathetic nervous system. By blunting the neuroendocrine response, it also affects postoperative immune function and ultimately long-term outcomes. ${ }^{[12]}$ In the present study,the significant decrease observed in mean pulse rates, systolic and diastolic blood pressure from the baseline readings seen in both the groups which could be due to increased initial values because of pain (VAS - 4) which reduced significantly after effective analgesic action of the drugs. ${ }^{[10,11]}$ Various studies have evidenced that epidural tramadol can provide adequate postoperative analgesia comparable to that of epidural morphine ${ }^{[13]}$ or fentanyl ${ }^{[15]}$.

\section{Limitations}

Study duration of three days, single blinded study, and heterogenic group of patients.

\section{Figures \& Tables}

[Fig. 1]

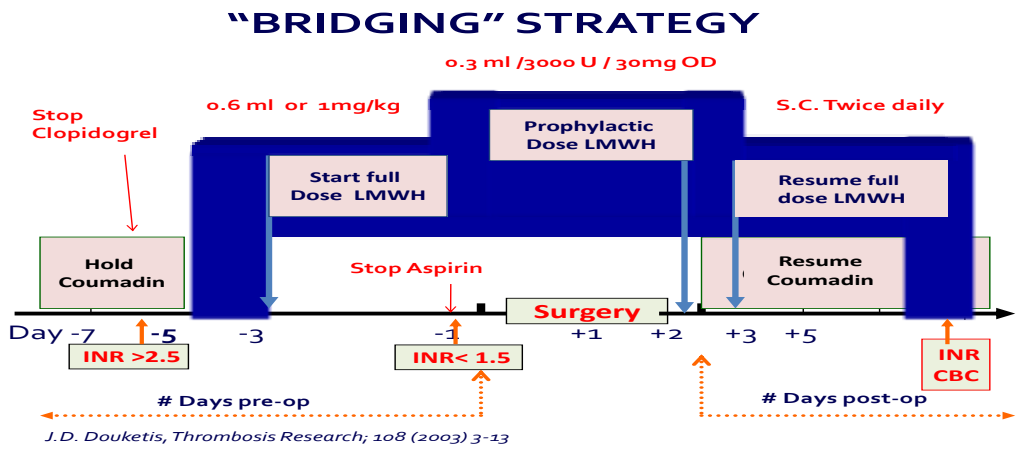

[Fig. 2]

Disease wise distribution of the selected patients -

\begin{tabular}{|l|l|l|}
\hline (n=165) & Group A ( $n=80)$ & Group B $(n=85)$ \\
\hline COPD \& CCF & 11 & 15 \\
\hline Dysrrhythmias & 5 & 8 \\
\hline OId MI, angina & 24 & 22 \\
\hline IHD, DM \& HT & 29 & 27 \\
\hline Severe HT & 10 & 12 \\
\hline Tight MS & 1 & 1 \\
\hline
\end{tabular}

[Fig. 3] 


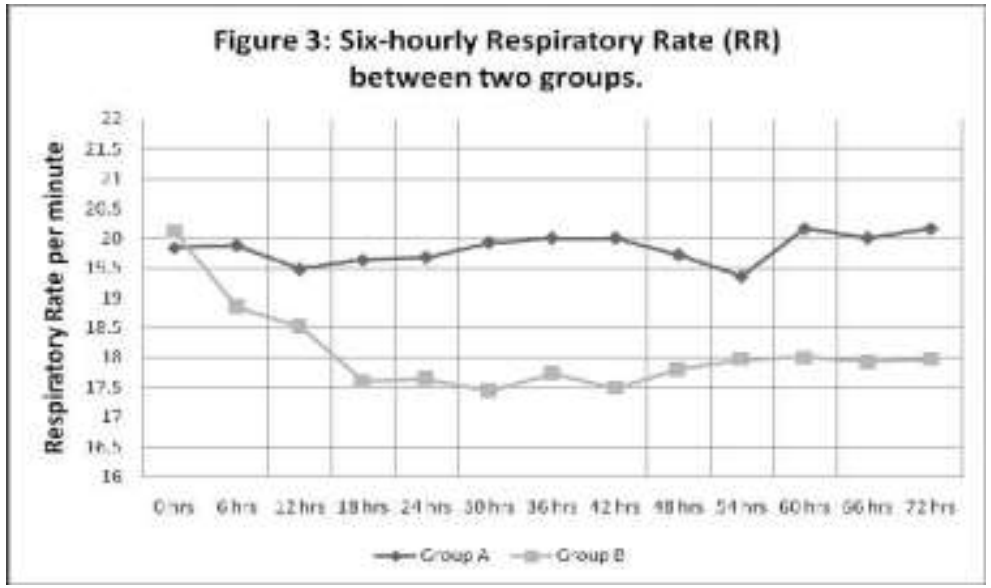

[Fig. 4]

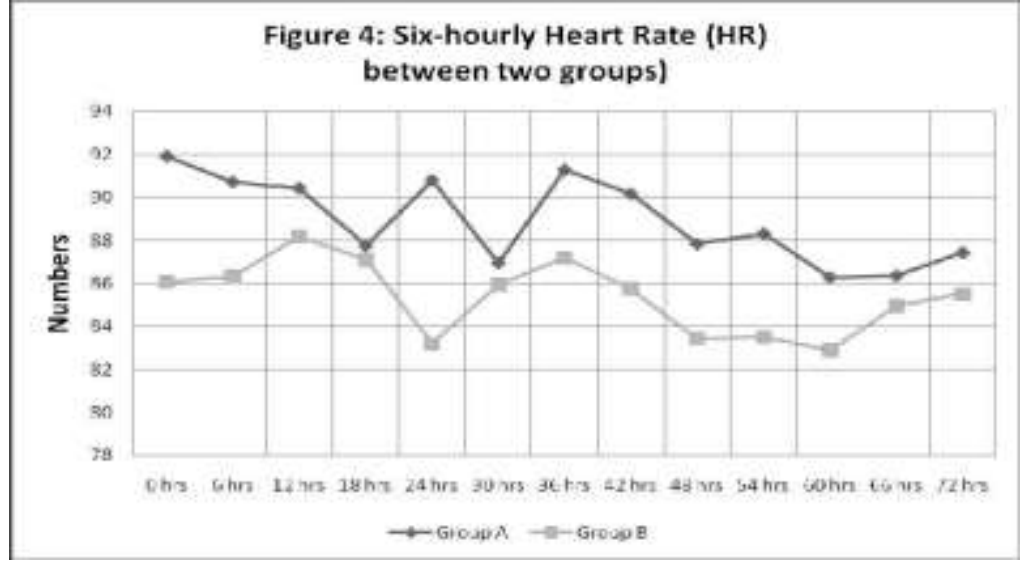

[Fig. 5]

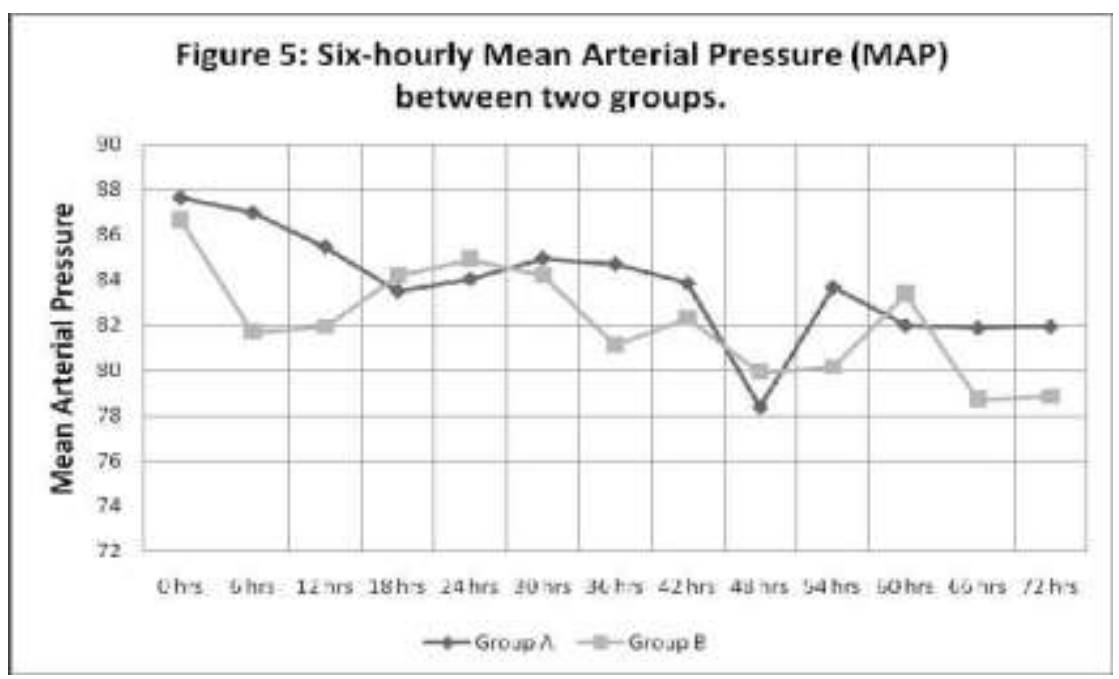

[Fig. 6] 
Observations

\begin{tabular}{|l|l|l|}
\hline & Group A $(\mathrm{n}=\mathbf{8 0})$ & Group B (n = 85) \\
\hline Motor block & $78+/-7$ min & $96.8+/-10 \mathrm{~min}$ \\
\hline Sensory block & $106+/-8 \mathrm{~min}$ & $328+/-16 \mathrm{~min}$ \\
\hline $\begin{array}{l}\text { Intraop. top ups } \\
\text { Pain relief 1st }\end{array}$ & Once in 74 pts & Nil \\
\hline Pain relief 2nd & Within 14-20 hrs & $\begin{array}{l}\text { Within 14 hrs in } \\
\text { 20 pts } \\
\text { pts \& In 16-20 }\end{array}$ \\
\hline Complications & In 8 pts & In 2 pts \\
\hline
\end{tabular}

[Fig. 7]

Intra \& Postoperative complications

\begin{tabular}{|l|l|l|l|l|}
\hline & \multicolumn{3}{|l|}{$\begin{array}{l}\text { Group A (n=80) } \\
\text { Intraop. }\end{array}$} & \multicolumn{2}{|l|}{ Group B (n=85) } \\
Intraop. & Postop. \\
\hline Fall in MAP & & 2 & 2 & 1 \\
\hline Rate \& rhythm & 5 & & 2 & \\
\hline Fall in SpO2 & 1 & 1 & 1 & \\
\hline Nausea & & & & 1 \\
\hline Dizzines & & 1 & & \\
\hline Angina & & 1 & & \\
\hline Pneumonitis & & 2 & & \\
\hline DVT & & 1 & & \\
\hline
\end{tabular}

\section{Conclusion}

Use of low dose local anaesthetics with Tramadol was safe, reliable \& effective in producing adequate sensory \& motor blockade. The technique provided better haemodynamic stability $(\mathrm{p}<0.07) \&$ postoperative pain relief $(\mathrm{p}<0.01)$ with lesser postoperative complications ( $8 \mathrm{Vs} 2)$. LDEA with Tramadol gave better outcome than controls in HRCP (High risk cardiac patients).

\section{Acknowledgements}

The authors are grateful to Dr. Alka Gore (Statistician, Department of Preventive \& Social Medicine), BVDUMC and all staff in Department of Orthopaedics (study place BVDUMC \& hospital).

\section{References}

[1] Jin F, Chung F. Minimizing perioperative adverse events in the elderly. Br J Anaesth 2001;87:608-24.

[2] Douketis JD. Thrombosis Research 2003:108;3-13.

[3] Goyal M, Taxak S, Kshetrapal K K, Goel MK. Continuous Spinal Anesthesia in a High Risk Elderly Patient Using Epidural Set. J Anaesthesiol Clin Pharmacol 2011;27:139-41.

[4] Sock Huang Koh, James Rogers. Anaesthesia for patients with cardiac disease undergoing non-cardiac surgery. Update in Anaesthesia 2002;14:1-2.

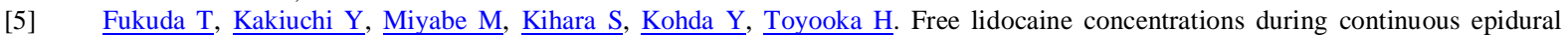
anesthesia in geriatric patients. Reg Anesth Pain Med 2003;28:215-20.

[6] Maharjan SK, Shrestha BM. Epidural anaesthesia and analgesia. Kathmandu University Medical Journal 2004;2:18-23

[7] Yokoyama M, Itano Y, Katayama H, Morimatsu H, Takeda Y, Takahashi T, Nagano O, Morita K. The Effects of Continuous Epidural Anesthesia and Analgesia on Stress Response and Immune Function in Patients Undergoing Radical Esophagectomy. Anesth Analg 2005;101:1521-7

[8] $\underline{\text { Rigg JR }}, \underline{\text { Jamrozik K }}, \underline{\text { Myles PS }}, \underline{\text { Silbert BS}}, \underline{\text { Peyton PJ, Parsons RW }}$, Collins KS. Epidural anaesthesia \& analgesia and outcome of major surgery: a randomized trial. Lancet 2002;359(9314):1276-82

[9] Chaturvedi S, Chaturvedi A. Postoperative pain and its management. Indian J Crit Care Med 2007;11:204-11.

[10] Susan M Nimmo. Benefit and outcome after epidural analgesia. Contin Educ Anaesth Crit Care Pain 2004;4:44-7.

[11] Shabir SA, Saleem BA, Hakim A, Hashia AM. Postoperative Analgesia In Laparoscopic Cholecystectomy: A Comparative Study Using Bupivacaine Instillation And Infiltration Versus Parenteral Analgesia (Tramadol). The Internet Journal of Anesthesiology 2011;29:2.

[12] Bauer M, George III JE, Seif J, Farag E. Recent Advances in Epidural Analgesia. Anesthesiology Research and Practice 2012, Article ID 309219,14.

[13] Yaddanapudi LN, Wig J, Singh B, Tewari MK. Comparison of efficacy and side effects of epidural tramadol and morphine in patients undergoing laminectomy: a repeated dose study. Neurol India 2000;48:398-400.

[14] Gupta R, Kaur S, Singh S, Aujla KS. A comparison of Epidural Butorphanol and Tramadol for Postoperative Analgesia Using CSEA Technique. J Anaesthesiol Clin Pharmacol 2011;27:35-8

[15] Rana RB, Rahman Z, Aziz L, Akhtaruzzaman AKM, Kazi MI. A Study on Epidural Tramadol Compared with Epidural Fentanyl Combined with Low Dose Bupivacaine for the Control of Metastatic Cancer Pain. BSMMU J 2009;2:66-72 